\title{
Diagnostic Test Equivalent Hemoglobin Reticulocyte in Iron Deficiency Anemia
}

\author{
Arundina Sanyoto*, Ketut Suega, Losen Adnyana, I Made Bakta \\ Hematology and Medical Oncology Division, Department of Internal Medicine, Faculty of Medicine, Udayana University, Jl. PB Sudriman, \\ Denpasar, Bali, Indonesia \\ *Corresponding author. E-mail: dinasanyoto.md@gmail.com
}

Received date: Jan 17, 2017; Revised date: Apr 30, 2017; Accepted date: May 3, 2017

\section{Abstract}

$\mathrm{B}$

ACKGROUND: Diagnosing iron deficiency anemia (IDA) is easy, but also can be complicated in condition with inflammation. A new modality for diagnostic which isn't influenced with inflammation is needed. The aim of this study is to find the cut-off point and evaluate the accuracy of reticulocyte hemoglobin equivalent (Ret-He) to diagnose IDA using ferritin as the gold standard.

METHODS: This study was an observational study with cross-sectional analytical design continued with the diagnostic test conducted in anemic individuals with age 18 years old or above.

\section{Introduction}

Iron deficiency anemia (IDA) has been a big problem in the world and also in Indonesia. World Health Organization (WHO) in 2005 estimated that approximately $24.8 \%$ of the global population affected by IDA.(1) Indonesia Basic Health Research in 2007 showed the prevalence of anemia in several periods of age or conditions, $59 \%$ in pregnant women, $70.1 \%$ in children, $59.9 \%$ in childbearing-age woman and $33.4 \%$ in male.(2) Based on a which specifically examined the prevalence of IDA in pregnant women in Bali, $46.2 \%$ of pregnant women suffered from mild IDA.(3) The impacts of iron deficiency include motor and cognitive development interruption, metabolic disorders, decreased endurance and other negative impacts.(4)
RESULTS: Eighty-seven patients (41 men and 46 women) were included in this study with mean of hemoglobin 7.42 $\mathrm{g} / \mathrm{dL}$, serum iron $42.71 \mathrm{mg} / \mathrm{dL}$, total iron-binding capacity (TIBC) $242.82 \mathrm{mg} / \mathrm{dL}$, ferritin $799 \mu \mathrm{g} / \mathrm{L}$ and Ret-He 23.63 pg. Ret-He with cut-off value 25 pg showed a sensitivity $97.2 \%$ (95\% CI $83.79-99.85 \%)$, specificity $66.67 \%$ (95\% CI $51.97-78.85 \%)$, positive predictive value $67.30 \%(95 \% \mathrm{CI}$ $52.77-79.28 \%$ ) and negative predictive value $97.14 \%$ (95\% CI $83.38-99.85 \%)$.

CONCLUSION: Ret-He showed the best sensitivity for detection of IDA and was suggested as the screening test for IDA.

KEYWORDS: IDA, Ret-He, diagnostic test

Indones Biomed J. 2017; 9(3): 143-6
IDA is anemia arising from depleted body iron reserves (depleted iron stores) so that the supply of iron for erythropoiesis is reduced, and ultimately the formation of hemoglobin is decreased.(5) The gold standard in the diagnosis of IDA is bone marrow staining to find hemosiderin. But due to several constraints, such as highly invasive procedures, inter-examiner variability and cost constraints, this test is being replaced. Ferritin is the best test in assessing the iron reserves. $(6,7)$ However, Ferritin is an acute phase protein, and the levels will be affected by a chronic inflammatory condition.(6-10) Now the world needs a new and easier modality to diagnose IDA. Reticulocyte hemoglobin equivalent (Ret-He) is a new test that measures the incorporation of iron in hemoglobin and reticulocytes. Ret-He can produce direct estimates of the availability of iron in erythron, which is expected to provide an easier way 
to diagnose IDA.(11) The absence of standardization of the cut-off is a constraint of using the Ret-He to diagnose IDA. The current study aims for accuracy value of RetHe (sensitivity, specificity, positive predictive value and negative predictive value) using the cut-off value from several studies. The study by Canals used Ret-He cut-off value $<25 \mathrm{pg}$ to distinguish between IDA and anemia of chronic disease (ACD). A study was conducted in chronic hemodialysis patient to diagnose iron deficient condition using Ret-He 27.2 pg as the cut-off point. Meanwhile, study by Urrechaga used Ret $\mathrm{He}<29$ pg to diagnose iron deficiency anemia in adult patients.(11-15) All of this cutoff points were tested in this study.

\section{Methods}

This study was a cross-sectional diagnostic study to determine the accuracy of Ret-He in diagnosing IDA compared with ferritin $<20 \mu \mathrm{g} / \mathrm{L}$ as gold standard according to Kerlin's Criteria. This research was conducted in subjects with anemia hemoglobin level $<10 \mathrm{gr} / \mathrm{dL}$ aged over 18 years who signed the informed consent in Sanglah Central General Hospital and Bangli Regency General Hospital from November 2015 through January 2016. Samples were taken consecutively until the number of samples met with minimal samples, which is 82 .

Blood samples were collected using ethylenediamine tetraacetic acid anticoagulant tubes (Vacutainer TM Becton-Dickinson, Rutherford, NJ, USA). Sysmex XN series is a fully automated blood cell counter. A sodium lauryl sulfate hemoglobin method was used to examine hemoglobin, hematocrit and erythrocyte index and a flowcytometry method using semi-conducted laser used to measure Ret-He. Serum iron, total iron-binding capacity (TIBC) and ferritin were measured by using Immulite 2000 with immunochemiluminescent. The data were analyzed by using SPSS 16.0. Normality test was done by using Kolmogorov-Smirnov test. The diagnostic test was done to get the sensitivity, specificity, positive predictive value and negative predictive value. Type of anemia was taken from the history and primary diagnosis of the patient.

\section{Results}

A total of 87 samples of patients were included in this study in which there were $41(47.1 \%)$ of male patients and 46 $(52.9 \%)$ female patients. The average age of patients was 46 years. More patient characteristics were shown in Table 1 .
The distribution of data by Kolmogorov-Smirnov test of age, hemoglobin, hematocrit, mean corpuscular volume, mean corpuscular hemoglobin, reticulocyte, Ret-He, serum iron, TIBC, ferritin, and transferrin saturation showed a normal distribution (Table 2).

A diagnostic test with a $2 \times 2$ table was used to assess the sensitivity, specificity, positive predictive value, negative

Table 1. Sample characteristics $(n=87)$.

\begin{tabular}{lc}
\hline \multicolumn{1}{c}{ Characteristics } & n (\%) \\
\hline Age (years) & $46.89 \pm 18.49$ \\
\hline Gender & \\
Male & $41(47.1)$ \\
Female & $46(52.9)$ \\
\hline
\end{tabular}

\section{Education}

No education

$14(16.1)$

Elementary and high school

$63(72.4)$

Bachelor

$10(11.5)$

\begin{tabular}{lc}
\hline Type of work & \\
Non-working and housewife & $40(45.5)$ \\
Farmer & $15(17.0)$ \\
Private sector & $21(23.9)$ \\
Professional & $11(12.9)$ \\
\hline Anemia Types & \\
IDA & $36(41.4)$ \\
ACD & $20(34.5)$ \\
Anemia in CKD & $11(12.6)$ \\
Hemorrhagic anemia & $4(4.6)$ \\
Mielosuppresion anemia & $1(1.1)$ \\
Hemolytic anemia & $2(2.3)$ \\
Anemia in cancer & $3(3.4)$ \\
\hline *IDA: Iron Deficiency Anemia; ACD: Anemia of Chronic Disease; \\
CKD: Chronic Kidney Disease
\end{tabular}

Table 2. Laboratory result parameter from all samples.

\begin{tabular}{lc}
\hline Laboratory Results Parameter & Value (SD) \\
\hline $\mathrm{Hb}(\mathrm{mg} / \mathrm{dL})$ & $7.42(1.73)$ \\
$\mathrm{Hct}(\%)$ & $23.66(5.70)$ \\
$\mathrm{MCV}(\mathrm{fL})$ & $75.48(11.61)$ \\
$\mathrm{MCH}(\mathrm{pg})$ & $23.75(5.38)$ \\
$\mathrm{SI}(\mu \mathrm{g} / \mathrm{dL})$ & $42.71(49.56)$ \\
$\mathrm{TIBC}(\mu \mathrm{g} / \mathrm{dL})$ & $248.82(117.41)$ \\
$\mathrm{Transferin}$ saturation $(\%)$ & $22.08(26.66)$ \\
Feritin $(\mu \mathrm{g} / \mathrm{dL})$ & $822.50(1843.15)$ \\
Ret-He $(\mathrm{pg})$ & $23.63(6.75)$ \\
Reticulocyte & $0.99(0.77)$ \\
\hline
\end{tabular}


predictive value, positive likelihood ratio and negative likelihood ratio. The cut-off was based on some studies that have been published, where $25 \mathrm{pg}, 26 \mathrm{pg}, 27.2 \mathrm{pg}$ and $29 \mathrm{pg}$ cut-off were analyzed tested in this study. Tables 3 through Table 6 described the results of the diagnostic test examined in this study.

Based on the analysis by using cross table $2 \times 2$, Ret$\mathrm{He}<25 \mathrm{pg}$ showed the best sensitivity, specificity, positive predictive value and negative predictive value compared to the other cut-off. The value showed that the sensitivity was 97.2\% (95\% CI: $83.79-99.85 \%$ ), specificity was $66.67 \%$ (95\% CI: $51.97-78.85 \%$ ), positive predictive value was $67.30 \%$ (95\% CI: 52.77-79.28\%) and negative predictive value was $73.81 \%$ (95\% CI 57.96-86.14\%).

\section{Discussion}

In the Ret-He $<25$ pg value obtains the figure of sensitivity, specificity, positive predictive value and negative predictive value that is best compared with other cut-off values taken

Table 3. Diagnostic test between Ret-He and ferritin with cutoff Ret-He $<25$ pg.

\begin{tabular}{lcccc}
\hline & \multicolumn{2}{c}{ Ferritin } & \multirow{2}{*}{ Total } \\
\cline { 2 - 3 } & \multicolumn{2}{c}{ Low } & Normal & \\
\hline \multirow{2}{*}{ Ret_He } & $<25 \mathrm{pg}$ & 35 & 17 & 52 \\
& $\geq 25 \mathrm{pg}$ & 1 & 34 & 35 \\
\hline \multicolumn{2}{c}{ Total } & 36 & 51 & 87 \\
\hline Sensitivity & $: 97.2 \%(95 \%$ CI: $83.19-99.85 \%)$ \\
Specificity & $: 66.67 \%(95 \%$ CI: $51.97-78.85 \%)$ \\
Positive predictive value & $: 67.30 \%(95 \%$ CI: $52.77-79.28 \%)$ \\
Negative predictive value & $: 97.14 \%(95 \%$ CI: $83.38-99.85 \%)$ \\
\hline
\end{tabular}

Table 4. Diagnostic test between Ret-He and ferritin with cutoff Ret-He $<26$ pg.

\begin{tabular}{lcccc}
\hline & \multicolumn{2}{c}{ Ferritin } & \multirow{2}{*}{ Total } \\
\cline { 2 - 3 } & \multicolumn{2}{c}{ Low } & Normal & \\
\hline \multirow{2}{*}{ Ret_He } & $<26 \mathrm{pg}$ & 35 & 20 & 55 \\
& $\geq 26 \mathrm{pg}$ & 1 & 31 & 32 \\
\hline \multicolumn{2}{c}{ Total } & 36 & 51 & 87 \\
\hline Sensitivity & $: 97.2 \%(95 \%$ CI: $83.79-99.93 \%)$ \\
Specificity & $: 60.78 \%(95 \%$ CI: 46.12-73.82\%) \\
Positive predictive value & $: 63.63 \%(95 \%$ CI: 49.51-75.85\%) \\
Negative predictive value & $: 96.87 \%(95 \%$ CI: $82-99.83 \%)$ \\
\hline
\end{tabular}

from other studies. This result is different compared to studies conducted by Canals, et al., which were obtained by the specificity and sensitivity of $81 \%$ and $76 \%$. Studies by Canals aimed to determine cut-off values of Ret-He and to determine its role in distinguishing between IDA and ACD. Canals strength of the study was a diagnostic test performed only on IDA and ACD groups to obtain a higher specificity value and also a greater number of samples, which was 504 subjects involved in the study with 127 subjects of them suffered from iron deficiency. Meanwhile, in this study a fewer number of patients with anemia (hemoglobin $<10 \mathrm{gr} /$ $\mathrm{dL}$ ) was involved and we classified the anemia into seven types of anemia including ACD and IDA. That was why the sensitivity values obtained in this study was better than the study conducted by Canals.(14)

Studies by Hatoun using a cut-off value of higher Ret-He, that was $<27.2 \mathrm{pg}$ because the study aimed to screen for iron deficiency conditions before IDA occurred.(15) Likewise on studies conducted by Urrechaga which used the value of Ret-He $<29$ pg because it was used to detect iron-restricted conditions erythropoiesis

Table 5. Diagnostic test between Ret-He and ferritin with cutoff Ret-He $<27$ pg.

\begin{tabular}{lcccc}
\hline & \multicolumn{2}{c}{ Ferritin } & Total \\
\cline { 2 - 3 } & \multicolumn{2}{c}{ Low } & Normal & \\
\hline \multirow{2}{*}{ Ret_He } & $<27 \mathrm{pg}$ & 35 & 25 & 60 \\
& $\geq 27 \mathrm{pg}$ & 1 & 26 & 27 \\
\hline \multicolumn{2}{c}{ Total } & 36 & 51 & 87 \\
\hline Sensitivity & $: 97.22 \%(95 \%$ CI: $85.47-99.93 \%)$ \\
Specificity & $: 50.98 \%(95 \%$ CI: 36.6-60.25\%) \\
Positive predictive value & $: 58.33 \%$ (95\% CI: 44.88-70.83\%) \\
Negative predictive value & $: 96.30 \%(95 \%$ CI: $81.03-99.91 \%)$
\end{tabular}

Table 6. Diagnostic test between Ret-He and ferritin with cutoff Ret-He $<29$ pg.

\begin{tabular}{lcccc}
\hline & \multicolumn{2}{c}{ Ferritin } & \multirow{2}{*}{ Total } \\
\cline { 2 - 3 } & \multicolumn{2}{c}{ Low } & Normal & \\
\hline \multirow{2}{*}{ Ret_He } & $<29 \mathrm{pg}$ & 36 & 28 & 64 \\
& $\geq 29 \mathrm{pg}$ & 0 & 23 & 23 \\
\hline \multicolumn{2}{c}{ Total } & 36 & 51 & 87 \\
\hline Sensitivity & $: 100 \%(95 \%$ CI: $87.99-100 \%)$ \\
Specificity & $: 45 \%(95 \%$ CI: 31.38-59.54\%) \\
Positive predictive value & $: 56.25 \%$ (95\% CI: 43.82-68.41\%) \\
Negative predictive value & $: 100 \%(95 \%$ CI: $82.19-100 \%)$
\end{tabular}


which is the first stage of iron deficiency journey.(13) By using the Ret-He values $<25 \mathrm{pg}$, the screening for IDA condition can be easily done. The value of a sensitivity of $97.2 \%$ indicates that the results of Ret-He $<25 \mathrm{pg}$ then there is a possibility of $97.2 \%$ of patients to experience the IDA. Thus, Ret-He which had a high sensitivity and negative predictive value showed it was an ideal marker for use as a screening test. In addition, Ret-He is quite available and quite extensive, economic, unaffected by inflammatory conditions and faster than with ferritin.

\section{Conclusion}

High sensitivity and negative predictive value of Ret-He at $25 \mathrm{pg}$ showed the potency of Ret-He to be used as a screening tool for IDA.

\section{References}

1. World Health Organization [Internet]. Geneva: World Health Organization; 2005. Worldwide prevalence on Anemia 1993-2005 [cited: 2015 Jun 15]. Available from: http://www.who.int/vmnis/ database/anaemia/anaemia_status_summary/en/.

2. Departemen Kesehatan RI [Internet]. Jakarta: Balai Penelitian dan Pengembangan Kesehatan Departemen Kesehatan RI. Riset; 2008. Kesehatan Dasar (RISKESDAS) 2007. Available from: https://www.k4health.org/sites/default/files/laporanNasional\%20 Riskesdas\%202007.pdf/.

3. Suega IK, Dharmayuda TG, Sutarga IM, Bakta IM. Iron deficiency anemia in pregnant women in Bali, Indonesia: a profile of risk factors and epidemiology. Southeast Asian J Trop Med Public Health. 2002; 33: 604-7.

4. Brugnara C. Iron deficiency and erythropoesis: new diagnostic approaches. Clin Chem. 2003; 49: 1573-8.

5. Bakta IM. Micrositic hypochromic anemia with iron metabolic sisorders. In: Clinical Hematology Concise. Jakarta: Penerbit Buku Kedokteran EGC; 2006. p.26-44.

6. Thomas C, Thomas L. Biochemical and hematologic indices in the diagnosis of functional iron deficiency. Clin Chem. 2002; 48: 106676.

7. Mast AE, Blinder MA, Dietzen DJ. Reticulocyte hemoglobin content. Am J Hematol. 2008; 83: 307-10

8. Brugnara C. A hematologic gold standard for iron deficiency states? Clin Chem. 2002; 48: 981-2.

9. Mast AE, Blinder MA, Lu Q, Flax S, Dietzen, DJ. Clinical utility of the reticulocyte hemoglobin content in the diagnosis of iron deficiency. Blood. 2002; 99: 1489-91.

10. Swart PDR, Rautenbach K, Raubenheimer JE. Reticulocyte haemoglobin content as a diagnostic tool for iron deficiency and iron deficiency anaemia in Ill infants and children. S Afr J CH. 2014; 8: 23-7.

11. Urrechaga E, Izquierdo S, Escanero JF. Looking back to our roots: 80 years of wintrobe's indices. EMJ Hema 2014; 1: 133-7.

12. Brugnara C, Schiller B, Moran J. Reticulocyte hemoglobin equivalent (Ret $\mathrm{He}$ ) and assessment of iron deficient states. Clin Lab Haem. 2006; 28: 303-8.

13. Urrechaga E, Borque EJF. Potential utility of the new Sysmex XE 5000 red blood cell extended parameters in the study of disorders of iron metabolism. Clin Chem Lab Med. 2009; 47: 1411-6.

14. Canals C, Remacha AF, Sarda MP, Piazuelo JM, Royo MT, Romero MA. Clinical utility of the new Sysmex XE 2100 parameterreticulocyte hemoglobin equivalent-in the diagnosis of anemia. Haematologica. 2005; 90: 1133-4.

15. Hatoun J, Sobota A, Meyers A. Using reticulocyte hemoglobin equivalent to screen for iron deficiency may be problematic. Glob Pediatr Health. 2014; 1: 2333794X14557030. doi: 10.1177/2333794X14557030. 